\title{
Lymphocytic Choriomeningitis Virus
}

National Cancer Institute

\section{Source}

National Cancer Institute. Lymphocytic Choriomeningitis Virus. NCI Thesaurus. Code C14230.

A species of single-stranded, negative-sense RNA viruses in the genus arenavirus and family arenaviridae. It is spread by rodents and causes meningitis and encephalitis. 